\title{
O Budista hiper-real
}

\section{Alexsânder Nakaóka Elias ${ }^{1}$}

\section{Resumo}

Este trabalho busca desmistificar o conceito corrente no mundo ocidental e no Brasil a respeito do Budismo, suas práticas culturais (incluindo a arquitetura e disposição física dos Templos) e seus adeptos. O intuito é o de mostrar que esta tradição ultrapassa a noção de "filosofia de vida", se constituindo em uma religião (com história, livro sagrado e diversas subdivisões) que se adapta ao contexto sócio-cultural no qual é inserida. Para tanto, utilizarei como exemplo sintomático a corrente budista japonesa Honmon Butsuryu-shu, através de pesquisa realizada junto a comunidade em questão.

Fundada a cerca de 2.500 anos atrás, pelo Buda Shakyamuni (que, no entanto, não tinha o intuito de fundar uma religião), o Budismo é composto por diversas subdivisões, indo além do dueto Zen Budismo e Budismo Tibetano, correntes que estão "na moda" nos países à oeste do globo, inclusive no Brasil.

Neste sentido, os adeptos desta religião, sejam fiéis ou sacerdotes (monges), não precisam necessariamente seguir uma vida monástica e ascética (repleta de proibições) para alcançar o ideal budista da Iluminação ou Nirvana. Para esclarecer tal situação, considero como ponto de partida o texto de Alcida Rita Ramos (2012) denominado “O índio hiper-real”, no qual a autora nos mostra a relação construída entre os brancos e os índios no Brasil, acentuando que a existência de um modelo de índio mantém "o

1 Doutorando em Antropologia Social//FCH (Unicamp), orientadora Maria Suely Kofes alexdefabri@yahoo.com.br, telefone: (19) 9-9413.3139 
simulacro que é o índio hiper-real: dependente, sofredor, vítima do sistema, inocente das mazelas burguesas, íntegro em suas ações e intenções e de preferência exótico (2012, p. 06)".

O mesmo ocorre com o conceito e o modelo de Budismo no mundo ocidental, normalmente dividido entre Zen Budismo japonês (adepto às práticas meditativas) e o Budismo Tibetano (alicerçado na figura emblemática e política do Dalai Lama). Tal Budismo é tratado por leigos e adeptos, via de regra, não como uma religião, mas como uma filosofia de vida. Além disso, espera-se que um budista "stricto sensu" seja um monge internado em um mosteiro asiático, que passa sua vida ascética longe dos conflitos do mundo (corrompido), rezando, meditando e reverenciando a imagem do Buda Histórico e de outros Budas, que para eles não representam, necessariamente, uma deidade.

Para contrapor tal análise, utilizo como referência a corrente budista Honmon Butsuryu-shu ${ }^{2}$, instituída no Japão pelo mestre Nichiren Daibosatsu e a primeira ramificação da religão no Brasil, chegando ao país no ano de 1908, através do sacerdote Ibaragui Nissui Shounin.

O grande intuito da HBS (abreviação de Honmon Butsuryu-shu) é mostrar, de forma evidente e enfática, a existência do que eles chamam de Budismo Primordial. Para os devotos desta corrente, há um Buda Primordial, primeiro, que é a origem de todos os Budas e origem também de toda e qualquer forma de existência. Isso significa que, além dos diversos Budas que habitam os vários mundos existentes, todos eles, inclusive o Buda Shakyamuni, são na verdade emanações do Buda Primordial.

\footnotetext{
${ }^{2}$ Significa, numa tradução literal, Religião Budista do Caminho Primordial do Sutra Lótus Estabelecida pelo Buda Primordial. Honmon significa "Caminho Primordial" do Sutra Lótus e faz referência ao trecho que vai do $15^{\circ}$ ao $22^{\circ}$ capítulo; Butsu significa "Buda Primordial"; ryu significa "estabelecido" ou "fundado" e Shu quer dizer "Religião" (disponível em http://www.budismo.com.br/significado.php).
} 
Sendo assim, o Buda Histórico seria "simplesmente" uma manifestação do Buda Primordial, que veio à Terra incumbido da missão de disseminar os ensinamentos do segundo. Ao terminar sua obra, seu legado, retornou imediatamente "ao interior do corpo do Buda Primordial"3.

\begin{abstract}
“Provisório (Shaku), significa 'rastro', ou seja, se há rastro, há um corpo que o deixou. São rastros que nos levam ao encontro do Buda Primordial. Podemos entender o significado da palavra provisório como sombra. Não há sombra sem corpo. O provisório é como se fosse a revelação de uma foto em relação ao verdadeiro objeto fotografado" (BUTSURYU-SHU, Honmon. Revista Lótus: ano 7, n. 70. São Paulo, 2005, p. 3).
\end{abstract}

Assim, nos templos da Honmon Butsuryu-Shu não existem estátuas do Buda Gautama nem de outros Budas, ao contrário da maioria dos santuários da religião. E a justificativa para este fato é que "não podemos venerar algo temporário, sujeito a mutabilidade. A forma de venerarmos o Buda Primordial é venerando na sua forma espiritual, não na estátua de Buda, pois o próprio Buda baniu tal forma de devoção ${ }^{4}$ ".

O Budismo HBS coloca, portanto, o Buda Primordial como uma espécie de divindade máxima, criadora, diferentemente das demais doutrinas budistas, que são atéias em relação a uma entidade suprema. A respeito desta particularidade, Gonçalves nos diz que "Nichiren fulminava com a mais radical condenação todos os que não seguissem sua doutrina, baseada no Saddharma-Pundarika-Sutra (Sutra do Lótus da Lei Excelente) e era, por sua vez, condenado por todas as escolas" (2007, p. 59).

De fato, o Buda Shakyamuni deixou uma vasta coletânea de ensinamentos orais, compilados em 84.000 sutras que juntos formam o Cânone Páli, a escritura sagrada do Budismo. As diversas correntes budistas,

\footnotetext{
${ }^{3}$ BUTSURYU-SHU, Honmon. Revista Lótus: ano 7, n. 70. São Paulo, 2005, p. 02.

${ }^{4}$ BUTSURYU-SHU, Honmon. Revista Lótus: ano 8, n. 81. São Paulo, 2006, p. 03.
} 
ao longo do tempo, passaram a dar maior ou menor importância a certos textos em detrimento de outros e, na HBS, não foi diferente. $\mathrm{O}$ ensinamento considerado principal pela Honmon Butsuryu-shu é chamado de "Sutra Lótus da Lei Excelente".

Para a HBS, portanto, o Buda Gautama, emanação do Buda Primordial, deixou clara a mensagem de que o Sutra Lótus é "o único Sutra a ser seguido, sem margem de possibilidade de adoção de outro tipo de ensinamento. O Sutra Lótus é o sutra que contém a iluminação completa do Buda Primordial. Os demais sutras que foram pregados por diversos motivos ou para o preenchimento de uma determinada necessidade, são considerados sutras provisórios" $"$.

Sendo assim, o Sutra Lótus buscaria salvar a todos através "daquilo que podem oferecer: a fé e a compaixão" (BUTSURYU-SHU, Honmon. Revista Lótus: ano 4, n. 33, p. 25. São Paulo, 2002).

Através da prática deste sutra todos poderão, em um futuro distante, atingir o ideal budista da Iluminação, mesmo vivendo na Era Mappou, o período de decadência (fim dos tempos), decorrente do distanciamento quase total dos ensinamentos do Buda Histórico.

Sendo assim, a HBS se instalou no Brasil com o intuito de expandir os ensinamentos contidos no Sutra Lótus e buscando se adaptar à cultura local, já que sua doutrina pressupõe que todos podem atingir o ideal da Iluminação, mesmo vivendo na sociedade moderna.

Neste caso, é importante destacar a forma como uma expressão religiosa oriental realiza um processo de adaptação e aceitação sócio-cultural no contexto brasileiro, dando relevância à existência de um vocabulário ocidentalizado (termos como ascese, arcebispo, sumo-pontífice, passeata,

\footnotetext{
${ }^{5}$ Disponível em http://www.budismo.com.br/sutra.php.
} 
conversão, catedral, Papa e Deus são utilizados pelos sacerdotes e fiéis da HBS), criado para representar os personagens religiosos no Brasil. Este vocabulário surpreende, pois utiliza termos de uma tradição muito assimilada pelo cristianismo, apropriada por uma religião oriental. Isso significa uma série de adaptações, traduções, incorporação de um vocabulário e, até mesmo, da arquitetura e composição dos espaços físicos dos templos, localizados em prédios e terrenos em cidades de grande concentração populacional (como São Paulo, Rio de Janeiro, Campinas e Curitiba).

Neste sentido, podemos estender as definições de Ana Cristina Lopes Nina (2006) que, embore trabalhe especificamente com o Budismo Tibetano e o seu contexto de diáspora pelo mundo, pode servir, aqui, como alircerce teórico para compreender as adaptações e reformulações encontradas na HBS do Brasil para se encaixar no contexto sócio-cultural brasileiro (tão distinto do japonês) e conquistar novos adeptos. Segundo a autora:

... fora de seu contexto original, qualquer cultura se transforma, antes de mais nada, em instrumento que possibilita a comunicação, e por isso é preciso levar em conta o que se tornará significativo no(s) novo(s) contexto(s) em que se verá inserida. Para que uma cultura desempenhe com sucesso tal tarefa, é necessário selecionar, no seu interior, esses elementos significativos que tornam possível a comunicação. No caso da cultura tibetana na diáspora, parece possível dizer que, nesse processo de seleção, foi precisamente o budismo que, por um processo de "condensação", passou a significar, no plano político assim como em termos espirituais, uma espécie de súmula da cultura tibetana, sua face mais visível ou aparentemente de mais fácil acesso, transformando-se na principal moeda de negociação, para os tibetanos, do seu lugar frente às sociedades ocidentais nas quais se viram inseridos. Em outras palavras, o budismo tibetano passou a constituir na diáspora, para os tibetanos e para o mundo, um traço diacrítico, definidor de identidade. Na diáspora, no entanto, não seria possível falar em uma única identidade. Em um certo sentido, a inserção no mundo moderno fez muito mais do que simplesmente colocar o budismo tibetano diante de um novo 
contexto. Na verdade, seu principal efeito foi trazer algumas das lógicas inerentes à modernidade, e mais especificamente a tendência à fragmentação e ao "confronto" com outras realidades culturais, para o cerne do budismo tibetano. Interessa-me aqui, portanto, o movimento de transformação necessariamente provocado por esses novos elementos que permeiam o budismo tibetano (2006, p. 31-32).

Além disso, é necessário destacar que a sangha (comunidade) budista da HBS não recebe quaisquer proibições. Carne, bebida, sexo, tabaco ou qualquer outra prática, vista como imoral por muitos segmentos do Budismo e de outras religiões, não são condenadas. Cada sacerdote ou leigo (fiel ou não) deve ter consciência e humildade para reconhecer os erros e excessos e viver uma existência com fé e equilíbrio. Além disso, o "diferente" também é aceito na comunidade em questão, que procura, em teoria e prática, não realizar distinções raciais, étnicas e/ou de orientação sexual, aceitando todos aqueles que acreditam nos preceitos budistas e no Sutra Lótus da Lei Excelente.

Palavras Chave: Budismo, tradição, religião 